\title{
GAMBARAN EFIKASI DIRI DAN PEAK EXPIRATORY FLOW RATE PASIEN PENYAKIT PARU OBSTRUKSI KRONIS (PPOK)
}

\author{
Emdat Suprayitno ${ }^{1}$, Azizah Khoiriyati ${ }^{2}$, Titiek Hidayati ${ }^{3}$
}

\begin{abstract}
${ }^{1,2}$ Program Studi Magister Keperawatan Universitas Muhammadiyah Yogyakarta Jl. Lingkar Selatan, Kasihan, Tamantirto, Bantul, Yogyakarta. Email: emdats@yahoo.com

${ }^{3}$ Fakultas Kedokteran dan IImu Kesehatan Universitas Muhammadiyah Yogyakarta Jl. Lingkar Selatan, Kasihan, Tamantirto, Bantul, Yogyakarta.
\end{abstract}

\begin{abstract}
Background: Chronic obstructive pulmonary disease (COPD) has become a huge public health problem in the world. In Asy-Syaafi Hospital, COPD is the most commonly found disease after bcronchitis among the patients in out patient unit of lung desease. Self efficacy showed patients' confidence in independently managing chronic desease. Wheter they want or not to start the treatment is determined by their self efficacy. Peak expiratory flow rate showed condition and problems of lung function and the narrowing or blockage of the airway.

Objective: Identify conditions and problems on self efficacy and Peak expiratory flow rate of COPD patients in Asy-Syaafi Hospital Pamekasan, East Java.

Method: This research was descriptive study used non analytic cross sectional design, with total sampling, involving 30 respondents. Data were collected with a questionnaire of the COPD self efficacy (CSES) and peak flow meter. Data analysis was performed with a univariate analysis.

Results: Self efficacy was in low category with score less than $99(86.7 \%)$ and peak expiratory flow rate was less than $<50 \%$ of the PEF $(90 \%)$.

Conclusion: Most of COPD self efficacy in Asy-Syaafi Hospital Pamekasan were in not good category and peak expiratory flow rate contained in red zone or the occurrence of major constriction of the airways.
\end{abstract}

Keywords: COPD, Self Eficacy, Peak Expiratory Flow Rate

\section{PENDAHULUAN}

Penyakit paru obstruktif kronis (PPOK) adalah masalah kesehatan secara global yang sejak tahun 2001 merupakan masalah utama dalam kesehatan masyarakat. Pada tahun 2020 PPOK diperkirakan menempati peringkat kelima di seluruh dunia dalam beban penyakit dan peringkat ketiga dalam penyebab kematian. ${ }^{1}$ Sesak nafas atau dyspnea merupakan masalah yang umum dijumpai pada penderita PPOK. ${ }^{2}$

Berdasarkan hasil survei penyakit tidak menular oleh direktorat jenderal pengendalian penyakit dan penyehatan lingkungan kementerian kesehatan di 5 rumah sakit provinsi di Indonesia (Jawa Barat, Jawa Timur, Lampung, dan Sumatra Selatan) pada tahun 2004 menunjukkan PPOK menempati urutan pertama penyumbang angka kesakitan yaitu (35\%), asma bronkial (33\%), kanker paru (30\%), dan lainnya $(2 \%){ }^{3}$

Berdasarkan profil Rumah Sakit AsySyaafi Kabupaten Pamekasan Provinsi Jawa Timur tahun 2014 didapatkan data 10 penyakit terbanyak pada tahun 2013 di unit rawat jalan adalah 577 pasien bronchitis dan 504 pasien PPOK. Data jumlah pasien PPOK 
di unit rawat inap mencapai 352 pasien yang menjadi jumlah terbanyak kedua setelah tuberculosis yaitu 623 pasien. Jumlah ratarata pasien PPOK di unit rawat jalan bulan Maret, April, dan Mei tahun 2016 mencapai 80 pasien.

Berdasarkan hasil wawancara dengan 4 orang pasien PPOK mereka mengatakan masalah yang sering dialami adalah sesak napas, terkadang batuk disertai dahak dan kadang tanpa dahak. Pasien mengatakan dampak dari PPOK yang diderita memengaruhi banyak aspek. Satu orang pasien mengatakan sejak satu bulan yang lalu tidak bisa bertani karena batuk yang tidak segera sembuh. Kedua pasien lainnya mengatakan sesak yang dideritanya sangat menganggu aktivitas sehari-hari seperti pada saat mandi, berjalan, dan membersihkan rumah.

Efikasi diri dirancang untuk menguji keyakinan individu untuk melakukan kegiatan yang dipilih sebagai usaha yang diinginkan. ${ }^{4}$ Efikasi diri yang tinggi akan berpengaruh terhadap peningkatkan kualitas hidup pasien PPOK. $^{5}$ Efikasi diri merupakan salah satu aspek pengetahuan tentang diri atau self knowledge yang paling berpengaruh dalam kehidupan manusia sehari-hari karena efikasi diri yang dimiliki ikut memengaruhi individu dalam menentukan tindakan yang akan dilakukan dalam mencapai suatu tujuan. ${ }^{6}$

Peak expiratory flow rate (PEF) atau arus puncak ekspirasi adalah titik aliran tertinggi yang dicapai seseorang selama ekspirasi maksimal dan titik ini mencerminkan terjadinya perubahan ukuran jalan nafas menjadi besar. Pengukuran ini sangat berkolerasi dan sama dengan forced expiratory volume in the first second (FEV1). ${ }^{7}$ Pasien PPOK memiliki ketidakmampuan mendasar dalam mencapai angka aliran udara normal selama pernafasan terutama pada saat fase ekspirasi. $^{8}$ Ketidakmampuan pasien dalam mencapai udara normal disebabkan karena adanya obstruksi pernafasan yang dapat mengakibatkan paru-paru mudah untuk mengempis, sehingga terjadi penurunan aliran puncak ekspirasi atau PEF. ${ }^{9}$

\section{BAHAN DAN CARA PENELITIAN}

Jenis penelitian ini adalah deskriptif dengan menggunakan design cross sectional non analitik. Populasi dalam penelitian ini adalah Pasien PPOK di Poli paru RSU AsySyaafi yang menjalani rawat jalan pada bulan September tahun 2016 sebanyak 30 pasien PPOK dengan total sampling. Peneliti menggunakan lembar informed consent sebagai tanda persetujuan dari pihak responden.

Peneliti menggunakan kuesioner COPD self efficacy scale (CSES) untuk mengukur efikasi diri yang terdiri atas 33 pernyataan dan terdapat 4 pilihan jawaban yaitu 4: Sangat yakin, 3: Yakin, 2: Agak yakin, dan 1: Tidak yakin dengan kategori: efikasi diri baik jika skor efikasi diri >99, efikasi diri tidak baik jika skor efikasi diri <99. Instrumen 
CSES telah dilakukan uji reliabilitas dengan Cronbach's Alpha berkisar dari 0,80-0,9. ${ }^{10}$

Peneliti menggunakan Peak flow meter Vitalograph dengan standard kalibrasi ISO 23747:2007 untuk mengukur nilai PEF. Nilai PEF dihitung dengan cara hasil PEF diukur (L/M) dibagi nilai prediksi (L/M) kemudian dikalikan $100 \%$ dengan kategori \%PEF yaitu: Zona hijau jika nilai persentase PEF mencapai $80 \%$ sampai $100 \%$ yang menandakan fungsi paru-paru baik. Zona kuning jika nilai persentase PEF mencapai $50 \%$ sampai $80 \%$ yang menandakan mulai terjadi penyempitan jalan nafas. Zona merah jika persentase PEF kurang dari 50\% yang menandakan saluran nafas besar telah menyempit. ${ }^{11}$ Berdasarkan latar belakang tersebut maka sangat perlu dilakukan penelitian untuk mengetahui kondisi dan permasalahan pada pasien PPOK khususnya pada efikasi diri dan nilai Peak Expiratory flow rate.

\section{HASIL DAN PEMBAHASAN}

Dari tabel 1. dapat diketahui bahwa mayoritas responden berusia lansia sebesar $86.7 \%$ (26 responden), sebagian besar jenis kelamin laki-laki $73.3 \%$ (22 responden), sebagian besar tingkat pendidikan $\leq$ SLTP (SD,SLTP) 80\% (24 responden), sebagian besar pekerjaan non PNS 93.3\% (28 responden), tinggi badan merata yaitu tinggi badan 142-155 cm 50\% (15 responden). Sebagian besar berat badan dalam IMT normal 53.3\% (16 responden), kategori merokok sebagian besar kategori sedang (200-600 batang rokok). Sebagian besar lama penyakit $\leq 2$ tahun $66.7 \% \quad(20$ responden).

Tabel 1. Karakteristik responden penelitian.

\begin{tabular}{|c|c|c|}
\hline Karateristik & $f$ & $\%$ \\
\hline \multicolumn{3}{|l|}{ Usia } \\
\hline Dewasa & 4 & 13.3 \\
\hline Lansia & 26 & 86.7 \\
\hline \multicolumn{3}{|l|}{ Jenis Kelamin } \\
\hline laki-laki & 22 & 73.3 \\
\hline perempuan & 8 & 826.7 \\
\hline \multicolumn{3}{|l|}{ Pendidikan } \\
\hline$<$ SLTP & 24 & 80 \\
\hline$\geq$ SLTP & 6 & 20 \\
\hline \multicolumn{3}{|l|}{ Pekerjaan } \\
\hline Non PNS & 28 & 93.3 \\
\hline PNS & 2 & 6.7 \\
\hline \multicolumn{3}{|l|}{ Tinggi badan } \\
\hline $142-155$ & 15 & 50 \\
\hline $156-169$ & 15 & 50 \\
\hline \multicolumn{3}{|l|}{ IMT } \\
\hline kurang $(<18.5)$ & 14 & 46.7 \\
\hline Normal ( $\geq 18.5$ ) & 16 & 53.3 \\
\hline \multicolumn{3}{|l|}{$\sum$ Merokok } \\
\hline $\begin{array}{l}\text { Ringan (0-200) } \\
\text { Sedang (200- }\end{array}$ & 12 & 40 \\
\hline 600$)$ & 18 & 60 \\
\hline \multicolumn{3}{|l|}{ Lama penyakit } \\
\hline$\leq 2$ tahun & 20 & 66.7 \\
\hline$>2$ tahun & 10 & 33.3 \\
\hline
\end{tabular}


Tabel 2. Efikasi diri pada pasien PPOK

\section{Efikasi diri}

\section{f}

Baik

4

13.3

Tidak baik

26

86.7
Data primer: 2016

Berdasarkan tabel 2. dapat diketahui bahwa sebagian besar responden memiliki efikasi diri yang tidak baik yaitu 86.7\% (26 responden). Persepsi efikasi diri mengacu pada berapa banyak keyakinan seseorang dapat melakukan tindakan untuk menghadapi situasi tertentu. ${ }^{5}$ Menurut teori health belief model (HBM) jika seseorang hanya memiliki pengetahuan, sikap, dan keterampilan tertentu tanpa adanya efikasi diri yang tinggi maka kecil kemungkinan seseorang tersebut akan melakukan tindakan atau perilaku tersebut. ${ }^{12}$ Efikasi diri merupakan keyakinan individu terhadap kemampuannya untuk mengelola penyakit kronis secara mandiri, karena menentukan seseorang untuk memulai atau tidak dalam melakukan perawatan. ${ }^{13}$

Banyak pasien PPOK yang kehilangan rasa kontrol terhadap penyakit dan kehidupan mereka. Pasien PPOK dengan gejala batuk, produksi dahak yang meningkat, dan sesak nafas dapat menurunkan kepercayaan kemampuan mereka untuk menghindari kesulitan bernafas selama terlibat dalam kegiatan tertentu dengan kemampuan yang minimal. Sebagai akibat dari efikasi diri yang rendah tersebut beberapa pasien memilih tidak beraktivitas meskipun secara fisik mereka mampu untuk melakukannya. ${ }^{14}$

Salah satu faktor yang memengaruhi efikasi diri pasien PPOK adalah tingkat pendidikan di mana proses pembentukan efikasi diri adalah melalui proses kognitif. ${ }^{15}$ Tingkat pendidikan responden mayoritas berada dalam tingkat pendidikan yang rendah (SD dan SLTP) sehingga dapat berpengaruh terhadap efikasi diri yang dimiliki. Pasien dengan tingkat pendidikan yang lebih tinggi akan memiliki efikasi diri dan perawatan diri yang lebih baik. Hal ini terjadi karena mereka lebih matang terhadap perubahan pada dirinya sehingga lebih mudah menerima pengaruh positif dari luar termasuk informasi kesehatan yang diperoleh. ${ }^{16}$

\begin{tabular}{|c|c|c|}
\hline Nilai PEF & f & $\%$ \\
\hline $\begin{array}{c}<50 \% \\
\text { (Zona merah) }\end{array}$ & 27 & 90 \\
\hline $\begin{array}{c}50-80 \% \\
\text { (Zona kuning) }\end{array}$ & 3 & 10 \\
\hline
\end{tabular}

Data primer: 2016

Berdasarkan tabel 3 dapat diketahui sebagian besar responden memiliki nilai \%PEF $<50 \%$ sebesar $90 \%$ (27 responden) yang merupakan kategori zona merah dan adanya tanda klinis terjadinya penyempitan saluran nafas besar di mana pada normalnya nilai \%PEF berada pada rentang nilai $>80 \%$ $100 \%$. 
Nilai PEF pada pasien PPOK menggambarkan seberapa berat obstruksi yang terjadi pada pasien tersebut ${ }^{(9)}$. Akibat adanya obstruksi yang terjadi pada saluran pernafasan terutama saat ekspirasi mengakibatkan terperangkapnya udara di bagian distal paru sehingga paru menjadi kolaps. Adanya air trapping mengakibatkan penurunan ventilasi alveolus yang ditandai dengan penurunan PO2 (hipoksemia) dan peningkatan PCO2 (hiperkapnia) dalam darah. ${ }^{17}$

Terjadinya hipoksemia, hipoksia, dan hiperkapnia akan menyebabkan terjadinya asidosis respiratorik sehingga meningkatkan proses pernafasan dan penggunaan otot-otot bantu pernafasan. ${ }^{7}$ Hipoksia yang terjadi di dalam tubuh akan menyebabkan hipoksia terhadap otot juga, sehingga akan terjadi metabolisme anaerob yang dapat menghasilkan asam laktat. Peningkatan asam laktat dalam tubuh akan menyebabkan kelelahan otot. Kelelahan otot yang terjadi di saluran pernafasan dapat menurunkan nilai PEF. ${ }^{9}$

Beberapa faktor yang dapat memengaruhi nilai PEF adalah usia. Ratarata usia responden termasuk dalam rentang usia lansia. Nilai PEF akan semakin berkurang dengan bertambahnya usia seseorang yang dapat dibuktikan dari tabel prediksi nilai PEF. Fungsi paru akan terus menurun sesuai bertambahnya usia seseorang karena dengan meningkatnya usia maka kerentanan terhadap penyakit akan bertambah karena sistem biologis manusia akan menurun secara perlahan dan terjadi penurunan elastisitas dinding dada. ${ }^{18}$

Perubahan struktur pernafasan seseorang dimulai pada usia dewasa pertengahan. Bertambahnya usia akan menyebabkan elastisitas dinding dada, elastisitas alveoli, dan kapasitas paru mengalami penurunan serta terjadi penebalan kelenjar bronkial $^{(9)}$. Perubahan tersebut mempunyai dampak terhadap peningkatan kerentanan terhadap penyakit dan mudah terjadi infeksi pada saluran pernafasan, sehingga memicu munculnya mukus yang dapat mengobstruksi saluran pernafasan. Obstruksi yang terjadi pada saluran pernafasan dapat menurunkan nilai dari PEF. ${ }^{18}$

Riwayat merokok juga menjadi pencetus penurunan PEF pada responden. Semakin banyak jumlah batang rokok yang dihisap dan semakin lama menjadi perokok akan semakin besar risiko mengalami PPOK. Kandungan zat nikotin dalam rokok dapat menurunkan fungsi sel epitel saluran pernafasan sehingga memicu terjadinya peradangan dan pengeluaran mukus yang berlebih sehingga mengakibatkan obstruksi jalan nafas. ${ }^{9}$

Hasil penelitian juga menunjukkan bahwa sebagian besar responden berjenis kelamin laki-laki yang semuanya adalah perokok dan mempunyai riwayat merokok dengan kriteria sedang yaitu 200-600 batang pertahun. Kebiasaan merokok merupakan 
salah satu faktor yang dapat menurunkan fungsi pernafasan pada seseorang. Semakin banyak jumlah batang rokok yang dihisap dan semakin lama riwayat merokok akan semakin besar risiko mengalami PPOK. ${ }^{9}$

Tinggi badan juga merupakan faktor yang dapat mempengaruhi fungsi paru. $^{9}$ Tinggi badan memiliki korelasi positif dengan nilai PEF. Bertambah tingginya seseorang maka arus puncak ekspirasi akan bertambah besar. Seseorang yang memiliki tubuh tinggi maka fungsi ventilasi parunya lebih tinggi dibanding dengan orang yang bertubuh pendek. $^{9}$

\section{KESIMPULAN}

Sebagian besar responden memiliki efikasi diri yang tidak baik sebesar 86.7\% (26 responden) di mana nilai skor efikasi diri tidak baik yaitu < 99 dan sebagian besar responden memiliki nilai \% PEF < 50\% sebesar $90 \%$ (27 responden) yang merupakan kategori zona merah dan adanya tanda klinis terjadinya penyempitan saluran nafas besar di mana pada normalnya nilai \% PEF berada pada rentang nilai > $80 \%$ $100 \%$.

Penelitian ini diharapkan menjadi tambahan informasi dan pengetahuan bagi institusi pendidikan dan institusi rumah sakit tentang efikasi diri dan nilai PEF agar dapat mengintegrasikan dampak dari rendahnya nilai efikasi diri dan nilai PEF pada pasien PPOK. Diharapkan pengkajian tentang efikasi diri pasien PPOK dapat ditambahkan sebagai pengkajian faktor psikososial pada asuhan keperawatan. Pengkajian tingkat keyakinan pasien pada ekspektasi efikasi diri diperlukan untuk meningkatkan perilaku perawatan diri dan kualitas hidup pada pasien dengan penyakit kronis khususnya PPOK.

\section{KEPUSTAKAAN}

1. Vestbo J, Hurd SS, Agustí AG, Jones PW, Vogelmeier C, Anzueto A, et al. Global strategy for the diagnosis, management, and prevention of chronic obstructive pulmonary disease:

GOLD executive summary. American Journal Of Respiratory And Critical Care Medicine. 2013;187(4): 347-65.

2. Ambrosino, Nicolino, Serradori $M$. Comprehensive treatment of dyspnoea in chronic obstructive pulmonary disease patients: University Hospital of Pisa:

Long Termhealth Care; 2006.

3. Pedoman pengendalian Penyakit Paru Obstruktif Kronis (PPOK). In: Direktorat Jenderal pengendalian dan Penyehatan Lingkungan Direktorat Pengendalian Penyakit Tidak Menular, editor. Jakarta: Depkes RI; 2006.

4. Garrod, Rachel, Marshall J, Jones F. Self efficacy measurement and goal attainment after pulmonary rehabilitation. The International Journal of Chronic Obstructive Pulmonary Disease. 2008;3 (4):791-6. 
5. Bentsena SB, Wentzel-Larsenc $T$, Henriksend $\mathrm{AH}$, Roknee $\mathrm{B}$, Wahl AK. Self-efficacy as a predictor of improvement in health status and overall quality of life in pulmonary rehabilitationan exploratory study. Patient Education And Counseling 2010; 81(1):5-13.

6. Cindi K, Rosra M, Rahmayanthi $R$. Peningkatan efikasi diri siswa dalam belajar dengan menggunakan layanan bimbingan kelompok pada siswa kelas $\mathrm{x}$ SMA 3 Negeri Bandar Lampung. 2012.

7. Smeltzer SC, Bare BG. Buku ajar keperawatan medikal bedah. Edisi 8. Jakarta: EGC; 2007.

8. Price SA, Wilson. Patofisiologi konsep klinik proses-proses penyakit. Edisi 6. Jakarta: EGC; 2006.

9. Guyton AC, Hall JE. Buku ajar fisiologi kedokteran. Edisi 11 ed. Jakarta: EGC; 2007.

10. Bentsena SB, Wentzel-Larsenc T, Henriksend $\mathrm{AH}$, Roknee $\mathrm{B}$, Wahl AK. Self-efficacy as a predictor of improvement in health status and overall quality of life in pulmonary rehabilitationan exploratory study. Patient Education And Counseling 2010;81(1) : 5-13.

11. Siregar FZ. Perbandingan arus puncak ekspirasi sebelum dan sesudah latihan fisik pada anak obesitas dan tidak obesitas. Medan Universitas Sumatera Utara; 2008.

12. Kara M, Asti T. Effect of education on self-efficacy of Turkish patients with chronic obstructive pulmonary disease. Patient Education and Counselling. 2004; 55 (1) :114-20.

13. Rini IS. Hubungan antara efikasi diri dengan kualitas hidup pasien penyakit paru obstruksi kronis dalam konteks asuhan keperawatan Di RS Paru Batu dan RSU dr.Saiful Anwar Malang Jawa Timur. Jakarta: Universitas Indonesia; 2011.

14. Kara M, Alberto J A. Family support, perceived self-efficacy and self-care behaviour of Turkish patients with chronic obstructive pulmonary disease. $\mathrm{J}$ Clin Nurs. 2007;16 (8) :1468-78.

15. Ariani Y. Hubungan antara motivasi dengan efikasi diri pasien DM tipe 2 dalam konteks asuhan keperawatan di RSUP. H. Adam Malik Medan. Jakarta: Indonesia; 2011.

16. Wu SV, et al. Self-efficacy, outcome expectations and self-care behaviour in people with type 2 diabetes in Taiwan. Journal of Clinical Nursing. 2007;16 (11) : 250-7.

17. Potter PA, Perry AG. Buku ajar fundamental keperawatan: konsep, proses, dan praktik. Edisi 4. Jakarta: EGC; 2005. 
18. Novarin C, Murtaqib, Widayati N. Pengaruh progressive muscle relaxation terhadap aliran puncak ekspirasi klien dengan asma bronkial di Poli Spesialis Paru B Rumah Sakit Paru Kabupaten Jember. Pustaka Kesehatan 2015 ; 3 (2) : 311-8. 